\title{
Assessing the Status of Growth of MSMEs in a Developing Country: Uganda as a Case Study
}

\author{
Sazir Nsubuga Mayanja \\ School of Post Graduate Studies, University of Kigali, Kigali, Rwanda
}

Email address:

saznsumay@gmail.com

\section{To cite this article:}

Sazir Nsubuga Mayanja. Assessing the Status of Growth of MSMEs in a Developing Country: Uganda as a Case Study. Science Journal of Business and Management. Special Issue: Business Policy\& Strategic Management. Vol. 8, No. 2, 2020, pp. 83-89.

doi: $10.11648 /$ j.sjbm.20200802.15

Received: January 6, 2020; Accepted: February 24, 2020; Published: May 18, 2020

\begin{abstract}
The study set out to assess the status of growth of MSMEs in developing countries with Uganda as the case study. A cross sectional descriptive design in which both qualitative and quantitative approaches were used to study a sample of 371 respondents who were systematically sampled from four districts of Wakiso, Mukono, Kampala and Jinja. A significant number of respondents, that is $23.2 \%$, stated that their MSMEs have been growing. The standardized beta coefficients for the six predictor variables used in the study indicate that a firm's capital base is the best predictor of the growth of MSMEs $(0.574)$, followed by EPS (0.491) followed by market share (0.352), then dividends to shareholders $(0.267)$, followed by sales $(0.087)$ and lastly the number of employees (-.063). The growth of MSMEs has been basically retarded by the inability to borrow and mode of financing where results found ignorance of the matching principle. It is recommended that MSMEs need to adjust the mode of financing to follow the matching principle such that long-term objects are funded using funds from long-term sources while short-term projects should be financed using funds from short term sources. Conversely, funding short term liquidity needs using long-term sources of finance leads to a high degree of financing leverage in the long run, hence long run insolvency and decline of business.
\end{abstract}

Keywords: Growth, MSMEs, Economy, Enterprises, Employment, Liquidity, Profit, Development

\section{Introduction}

It has been observed that Small- and Medium-sized Enterprises (MSMEs) have an important role to play in achieving the Sustainable Development Goals (SDGs) in all countries, regardless of whether they are undeveloped, emergent or developed economically. They do so by promoting inclusive and sustainable economic growth, providing employment and decent work for all, promoting sustainable industrialisation and fostering innovation, and reducing income inequalities.[1] Cutting across geographic areas and sectors, and providing opportunities for skills development, MSMEs upgrade productivity in a large population of small businesses, including in traditional segments and the informal economy. They play crucial role in achieving both economic growth and social inclusion objectives, including escaping from low productivity traps and improving the quality of jobs for low-skilled workers.[2]

A major challenge is that there is no global definition of what MSMEs are. Country context plays a major role in determining the nature of these characteristics, especially, the size of investment in capital accumulation and the number of employees. For the particular case of this research, the Uganda Bureau of Statistics (UBOS) approach using number of employees, capital investment and annual turnover has adopted. Accordingly, in quantitative terms, micro enterprises are those businesses employing not more than 5 people and their total assets do not exceed ten million Uganda shillings (approximately \$2,500). Small enterprises employ between 5 and 49 people and total assets between ten million Uganda shillings (approximately $\$ 2,500$ ) but not exceeding one hundred million Uganda shillings (approximately $\$ 25,000$ ). The medium enterprises are those employing between 50 and 100people with total assets of more than one hundred million Uganda shillings (approximately $\$ 25,000$ ) but not exceeding three hundred and sixty million Uganda shillings (approximately $\$ 90,000$ ). It is estimated that $65 \%$ of MSMEs in Uganda are located in the districts which are the subject of 
the research. Hence the study population was composed of 650,000 MSMEs [3]. Of the about one million MSMEs in Uganda, about $80 \%$ are located in urban and semi-urban centers. About $80 \%$ of the MSMEs are in the manufacturing sector and $20 \%$ are in the services and other sectors. Most urban-located MSMEs are registered with government and these are the ones generally considered strong.

In Uganda, Micro, Small, Medium, Enterprises (MSMEs), which are the engine of growth in the country, spread across all sectors with $49 \%$ in service sector, $33 \%$ in commerce and trade, $10 \%$ in manufacturing and $8 \%$ in others and they employ over 2.5 million people. They account for approximately $90 \%$ of the entire Private Sector, generating over $80 \%$ of manufactured output that contributes $20 \%$ of the gross domestic product (GDP).[4] At the continental level, the MSMEs sector accounts for over $90 \%$ of all the enterprises of which between $70-80 \%$ are micro and very small enterprise, while medium enterprises account for between $5-15 \%$. They provide the main source of jobs and income for Africans. African women entrepreneurs own more than half of the micro and small enterprises. They play an increasing role in diversifying production and represent $70 \%$ of the active population in rural areas [5]

\section{Literature Review}

With respect to growth of business enterprises including MSMEs, various indices have been used by scholars. Some of these are growth in market share, capital base, number of employees, net income and dividends. Some are explored here.

Sales level of the firm is a simple and good indicator of its growth level. The absolute amount in monetary terms and the changes therein give litmus test of the direction in which the firm is moving [6]. However, without comparing a firm's sales with others in the market, will be less than conclusive. Thus, another metric, market share, the portion or percentage of sales of a particular product or service in a given region or market that are controlled by a company, is important. [7]. Market share is used by businesses to determine their competitive strength in a sector as compared to other companies in the same sector. It also allows a firm to accurately assess its growth from year to year. If the firm only uses sales to measure its performance, then it does not take into account the market conditions that may have improved or decreased its sales. Its sales may have gone up because of increased popularity of its type of product or service, or they may have gone down because of factors such as drought or recession. Since those factors are beyond the firm's control, they do not give meaningful information about how the firm is actually doing as a company in terms of improving its business. By measuring market share, the firm can establish whether it is doing better or worse compared to other companies that are facing the same challenges and opportunities that it is facing.

Change in an enterprise's capital base may give an indicator of whether a firm's capacity is changing for worse or better, for example by the number of times initial capital has multiplied itself to give a final change in total capital or assets also reflected through retained earnings and reserves. This is clearly an expansion in capital base, which is one of the indictors of a firm's growth. [8]. However, the amount of capital per se may not reveal whether an enterprise is growing or not. According a firms' growth is measured by the number of times initial capital has multiplied itself to give a final change in total capital or assets also reflected through retained earnings and reserves. This is clearly an expansion in capital base, which is one of the indictors of a firm's growth. Given the continuously increasing number of technological innovations, the number of employees in a firm may reduce in importance as a factor in assessing whether a firm is growing or not. The assertion is much in contrast to conclusion by some researchers that firms, which employ a large number of employees, are considered to have grown up and the large number of employees implies that the number of activities undertaken by such firms is more than for firms with fewer numbers of employees. [9] According to some researchers growth in profit or net income is even more important than sales because net income tells you how much money is left over after all of the operating costs are subtracted from sales [10]. Overall investors are quite interested in a firm that pays dividend. Sales should generate profit and dividends are paid out of profit. Therefore, dividend growth is a good indicator of financial health of a company. Some companies do not pay stock dividend at all. Rather, they use these excess profits to reinvest money back into the company to hopefully accelerate growth. One thing about Dividends (\%) is that it does not go negative. That is, once a dividend rate is established, a company needs to have a very good reason to decrease the dividend payout [11].

\section{Justification and Significance of the Study}

Overall study of success factors of MSMEs helps investors, providers of finance and government institutions to adopt strategies that contribute to enhancing the growth of these enterprises, protecting them from managerial problems and financial failure, as well as directing the local community institutions to support them. [12] Given the strategic importance of MSMEs in any economy, research in this area is justified. Many exploratory findings indicate that there is virtually no research approaching the issue from the angle of this particular research. The study therefore set out to establish how the growth status of MSMEs in selected districts of Uganda. Study results may lend a hand to policy makers and SME managers and owners while formulating policy guide lines to enhance liquidity of MSMEs. It is also intended to complement existing literature on management of liquidity of MSMEs for future researchers and academicians, not only in Uganda but elsewhere as well. 


\section{Conceptual Framework}

DEPENDENT VARIABLE

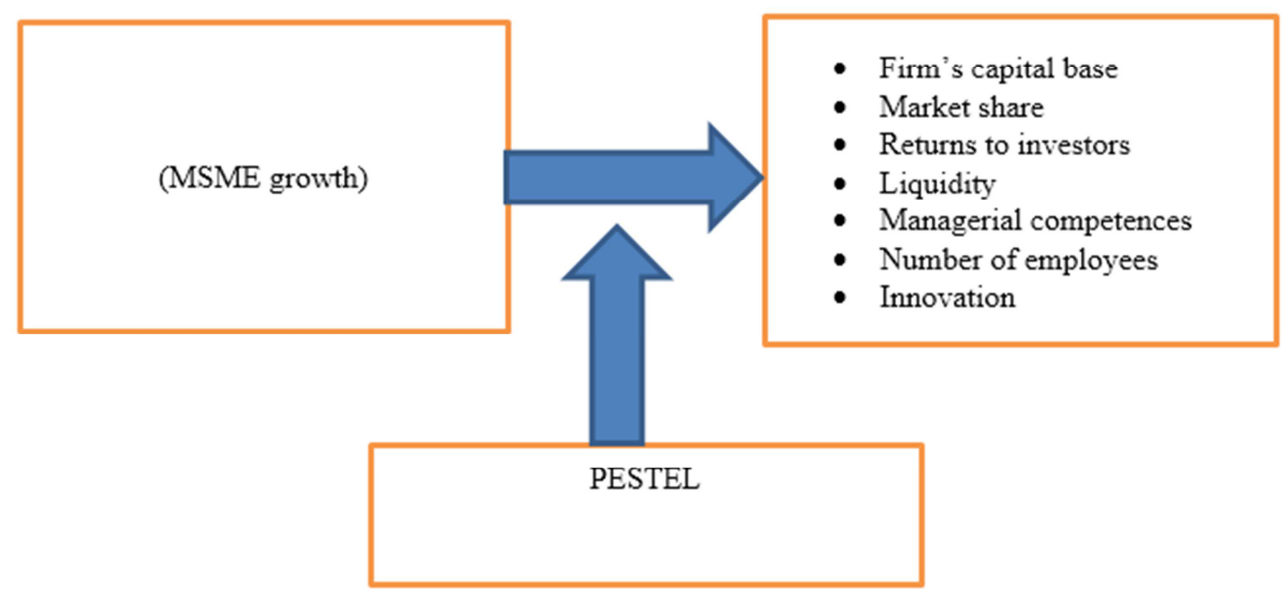

Figure 1. Conceptual framework.

A conceptual framework is a logical structure of what the researcher believes can best explain relationship between variables of study. The natural progression of the phenomenon to be studied [13]. It is intended to ease appreciation of the relationships through a picture or visual display of how ideas in a study relate and it assists the researcher in identifying and constructing his/her worldview on the phenomenon to be investigated [14]. It relates the independent variable (IV) with the dependent variable (DV) For example, the relationship between the dependent variable Micro-Small-Medium Enterprises (MSMEs growth) and the independent variable (firm's capital base, market share, returns to investors, liquidity, managerial competences, number of employees and innovation) is a symmetrical relationship where by a change in the later is followed by the former [15]. There are factors which have affect the dependent variables, and their impact is similarly felt in other spheres generally, and is generically referred to as PESTEL (Political, Economic, Social, Technological, Ecological and Legal). They are often referred to as intervening variables.

\section{Research Methodology}

In this section the researcher analyses the research design, area of study, study population, selection of the sample, data sources, research tools and methods, methods that were used for testing validity and reliability of research findings, research procedure and data analysis techniques that were adopted on the study.

\subsection{Research Design}

The study adopted a descriptive design in which both qualitative and quantitative approaches were used. The design provided an appropriate basis for the measurement of variables at a given point in time. The quantitative part of the study included the use of frequencies, percentages, means correlations and regressions to arrive at conclusions. The qualitative nature of the research was intended at clarifying the quantitative approach through descriptions, discussions, conclusions and recommendations.

\subsection{Area of Study and Study Population}

The study sampled the districts of Wakiso, Mukono, Kampala, and Jinja. These are the districts with the majority of MSMEs in the country and their impact is not only sheer number of MSMEs but also on the amount of turnover which they generate. Thus, picking samples of MSMEs from these districts was hypothesized to help make deductive conclusions on other MSMEs in other locations. These districts were purposively selected.

\subsection{Sample Size and Selection Method}

A sample of 400 respondents was arrived at using the formula for large populations [16] This is stated as follows:

$$
\mathrm{n}=\mathrm{pq} /(\mathrm{SE})^{2}
$$

Where

$\mathrm{n}$ is the sample size

$\mathrm{p}$ is the proportion of the population possessing the major attribute

$$
\mathrm{q}=1-\mathrm{p}
$$

SE is the standard error of the proportion.

For large populations whose proportion of the population possessing the attribute is unknown, the confidence interval should be set at $5 \%$ and the confidence level at $95 \%$. [17]

$\mathrm{SE}$ is computed as follows:

$\mathrm{SE}=5 \% / 1.96$, where $1.96=\mathrm{Z} \frac{\mathrm{a}}{2}$ also known as the critical value, the positive $\mathrm{z}$ value that is at the vertical boundary for the area of $\frac{a}{2}$ in the right tail of the standard normal distribution

This implies the SE $=0.025$. Note that when one cannot 
estimate the population, one sets $p$ at 0.5 .

This further implies that $n=(.5)(.5) /(0.025)^{2}=400$.

Sample selection from each district was systematically done as follows:

Table 1. The sample selection per district.

\begin{tabular}{llll}
\hline District & $\begin{array}{l}\text { No of } \\
\text { MSMEs }\end{array}$ & $\begin{array}{l}\text { Number of respondents } \\
\text { from each SME }\end{array}$ & $\begin{array}{l}\text { Total Number of } \\
\text { respondents }\end{array}$ \\
\hline Jinja & 50 & 2 & 100 \\
Kampala & 50 & 2 & 100 \\
Mukono & 50 & 2 & 100 \\
Wakiso & 50 & 2 & 100 \\
Total & 200 & & 400 \\
\hline
\end{tabular}

Sources of data

Both primary and secondary sources of data were employed in the study. Primary source consisted of the respondents sampled from MSMEs while secondary data consisted of textbooks, journals, magazines, newsletters and other publications. The former provided first hand information relating to study variables while the later provided information that could not be captured from primary sources.

\subsection{Research Tools and Methods}

Both close and open-ended questionnaires were used to solicit responses from respondents. The close-ended questions enhanced precision and conciseness while openended questions helped to clarify the responses provided in close-ended questionnaires.

The questionnaires were self-administered and this enhanced response through clarification of the questions especially to respondents that could not read and write. The use of self-administered questionnaires also justifies the neglect of interview guide since interviews were held with respondents as the questionnaires are being administered. To enhance data analysis, a uniform rating scale (the 5 point Likert scale) was adopted in preparation of questionnaires. In this, the following codes were defined as follows: 5 denoted strongly agree, 4 denoted agree, 3 denoted undecided, 2 denoted disagree while 1 denoted strongly disagree.

\subsection{Validity and Reliability}

Reliability refers to the level of dependability of the questions in the research instrument or the degree to which a measurement instrument gives the same results each time that it is used, assuming that the underlying thing being measured does not change. [18] Validity determines whether the research truly measures what it is intended to measure or how truthful the research results are [19]. To ensure validity in research, examination of trustworthiness is crucial. While establishing good quality studies through reliability and validity in research, Joppe states that the "trustworthiness of a research report lies at the heart of issues conventionally discussed as validity and reliability". Rigour, which refers to the extent to which the researchers worked to enhance the quality of the studies, is achieved through measurement of the validity and reliability. [20]

Furthermore, to ensure validity of research instruments, the researcher constructed instruments that were used to solicit data from the sample of respondents. The instruments were given to two selected lecturers to ascertain the truthfulness and clarity of the questions and to find out whether they seek the information that would answer the questions in the study. There are various types of validity but most commonly used are content validity and face validity. Content validity looks at whether the instrument adequately covers all the content that it should with respect to the variable. Face validity, is where experts are asked their opinion about whether an instrument measures the concept intended. [21] Content validity index (CVI) was used to establish validity of the instruments. Cronbach's $(\alpha)$ is the most commonly used test to determine the internal consistency of an instrument. It is used to arrive at the average of all correlations in every combination of splithalves. Cronbach's $\alpha$ result is a number between 0 and 1. An acceptable reliability score is one that is 0.7 and higher. [22]

$$
\text { Content validity index }(\mathrm{CVI})=\frac{\text { Sum of agreement on every relevant judgment }}{\text { Total number of items (questions) }} \times 100
$$

After the results, recommendations were incorporated and validity re-determined until an appropriate index is achieved. It was put at above $75 \%$. [23] The resultant CVI was $95.7 \%$ implying that the contents in the research instruments were valid in relation to study variables. To ensure this, the Cronbach alpha coefficient $(\alpha)$ for testing internal consistency was computed as follows:

$$
\propto=\frac{K}{K-1}\left(\frac{1-\sum S D^{2} I}{\sum S D^{2} T}\right)
$$

Where $\alpha=$ Alpha coefficient

$\mathrm{K}=$ Number of items in the instrument

$\sum=$ Summation sign

$\mathrm{SD}^{2} \mathrm{i}=$ Standard deviation squared within each item

\section{$\mathrm{SD}^{2} \mathrm{t}=$ Total Standard deviation}

The resultant coefficient should be above 0.75 if the contents of the instruments are to be considered reliable as asserted by Cronbach. Test statistics revealed alpha coefficient of 0.824 implying internal consistence in the scaling of items hence reliability of the study instruments.

The researcher requested permission from the organizations' management and made contacts with the respondents. Instruments were then developed, pilot tested and data collected. Data was analyzed and the final report written.

\subsection{Data Analysis}

Both quantitative and qualitative data was analyzed. 
Quantitative analysis is designed to collect cold, hard facts. Numbers Quantitative data is structured and statistical. Qualitative approaches have been commended for generating rich, detailed data that leave the participants perspective intact and providing a context for the phenomena being studied [24] Quantitative data was processed using the statistical package for social scientists (SPSS) to come out with the necessary frequencies, percentages, graphs and other descriptives. Analysis of Variance (ANOVA), Chi- square and regression analysis were used to test the difference between means and the relationship between the dependent and multiple independent variables while Pearson correlation coefficient was used to test the significance of the relationship between two variables. Qualitative data was thematically analyzed to make inferences from what was stated by respondents. These inferences were later integrated with quantitative findings to arrive at relevant conclusions. [25]

\subsection{Study Limitations and Solutions}

The study sample was large and located in different districts that posed a challenge in collecting data and finish the study in time. Libraries are not well stocked with latest text books that would provide a hand in gathering related literature. However, the researcher improved literature review with information from electronic journal articles on the internet although most of the best articles required subscription that raised the research budget from what had been anticipated.

Finally, there was a lot of hesitation from the respondents as to the purpose of the information required until it was explained to them that the data and information provided were purely for academic purposes and they were promised confidentiality regarding the information elicited from them. That way a reasonable level of response was achieved.

\section{Findings of the Study}

The general growth stratus was evaluated using the following scale on the basis of 5 for strongly agree, 4 for agree, 3 for undecided, 2 for disagree and 1 for strongly disagree. The question was whether respondents have generally examined growth of their MSMEs. Descriptive statistics have been used to trace the trend of predictors growth of MSMEs and ANOVA table has been helped to show the overall variance accounted for in the model. As a means to interrogate the findings Standard Regression has been used with regard to the effect of each individual Predictor Variable Coefficients.

Table 2. Results on the general growth status of MSMEs.

\begin{tabular}{llllll}
\hline & & Frequency & Percent & Valid Percent & Cumulative Percent \\
\hline Valid & Strongly Disagree & 53 & 14.3 & 14.3 & 55.8 \\
& Disagree & 207 & 55.8 & 6.7 & 6.7 \\
& Undecided & 25 & 13.2 & 13.2 & 70.1 \\
& Agree & 49 & 10.0 & 10.0 & 90.0 \\
& Strongly Agree & 37 & 100.0 & 100.0 \\
\hline
\end{tabular}

Source: Field data

Results in table 2 show that most respondents disagreed (70.1\%) that they have examined growth of their MSMEs although some significant number of respondents $23.2 \%$ stated that their MSMEs have been growing. Only 6.7\% were not decided on the growth status of their MSMEs. Generally, it can be hypothesized from the results that MSMEs have not grown to the expected levels given that a larger number
$(70.1 \%)$ stated so. Descriptive statistics were obtained for each of the trend of predictor variables regarding their level as a measure of growth. The following rating scale was adopted: 5 for strongly agree, 4 for agree, 3 for undecided, 2 for disagree and 1 for strongly disagree. Descriptive statistics on the trend of predictors growth of MSMEs

Table 3. Descriptive statistics on the trend of predictors growth of MSMEs.

\begin{tabular}{|c|c|c|c|c|c|}
\hline & $\mathbf{N}$ & Minimum & Maximum & Mean & Std. Deviation \\
\hline On average, our firm has a high amount of earnings per share & 371 & 1 & 5 & 2.38 & 1.294 \\
\hline On average, our firm's market share has been increasing & 371 & 1 & 5 & 2.44 & 1.206 \\
\hline On average, our firm's sales have been increasing & 371 & 1 & 5 & 2.33 & 1.211 \\
\hline On average, our firm's number of employees has been increasing & 371 & 1 & 5 & 2.09 & 1.616 \\
\hline On average, our firm's capital base has been increasing & 371 & 1 & 5 & 4.75 & .628 \\
\hline On average, our firm's dividend to Shareholders has been increasing & 371 & 1 & 5 & 2.42 & 1.549 \\
\hline
\end{tabular}

Source: Field data

Results in table 3 show that most respondents on average disagreed their MSMEs have a high value of EPS with mean response at 2.38, while they also disagreed that their market share has been increasing with mean response at 2.44 . Results further indicate that most respondents disagreed that MSMEs sales have been increasing with mean response at 2.33 while those that disagreed that the number of employees has been increasing registered mean response at 2.09. Respondents 
however strongly agreed that their capital base has been increasing revealed mean response at 4.75 although they disagreed that dividends to shareholders have been increasing with mean response at 2.42 . The findings concur with research which concluded that for high growth, although effective liquidity management and differentiation remain as key factors, they are joined by a product focus, with a number of important implications for SME strategy, most notably that there may not be one set of strategies that maximise both profitability and growth. The findings also confirm findings that SMEs perceive finance to be a very significant growth.

To investigate the effect of the predictor variables on the dependent variable growth, a regression analysis was conducted. Results were as shown in below:

Table 4. Model Summary of the effect of predictor variables on growth of MSMEs.

\begin{tabular}{lllll}
\hline Model & R & R Square & Adjusted R Square & Std. Error of the Estimate \\
\hline 1 & $.648(a)$ & .419 & .410 & .910 \\
\hline
\end{tabular}

a Predictors: (Constant), On average, our firm's dividend to Shareholders has been increasing, On average, our firm has a high amount of earnings per share, On average, our firm's capital base has been increasing, On average, our firm's market share has been increasing, On average, our firm's sales have been increasing, On average, our firm's number of employees has been increasing

The first $\mathrm{R}$ in table 4 is the multiple correlation coefficient that between all the predictor variables and the dependent variable. This value is 0.648 which indicates that there is a variance shared by the independent variables and the dependent variable. The second value, R- Square, is simply the squared value of $\mathrm{R}$ which is used to explain the goodness of fit or the amount of variance explained by the given predictor variables. This value is 0.419 which indicates that $41.9 \%$ of the variance in the growth of MSMEs is explained by dividends to shareholders, EPS, capital base, the trend of sales, the trend of employees and the market share. It has been observed that most SMEs are faced with a myriad of challenges and collapse within the first few months of operation. Most of these challenges are financial.

Table 5. ANOVA table showing the overall variance accounted for in the model.

\begin{tabular}{|c|c|c|c|c|c|c|}
\hline \multicolumn{7}{|c|}{ ANOVA (b) } \\
\hline Model & & Sum of Squares & Df & Mean Square & $\mathbf{F}$ & Sig. \\
\hline \multirow[t]{2}{*}{1} & Regression & 217.479 & 6 & 36.247 & 43.802 & .000 (a) \\
\hline & Total & 518.695 & 370 & & & \\
\hline
\end{tabular}

a Predictors: (Constant), On average, our firm's dividend to Shareholders has been increasing, On average, our firm has a high amount of earnings per share, On average, our firm's capital base has been increasing, On average, our firm's market share has been increasing, On average, our firm's sales have been increasing, On average, our firm's number of employees has been increasing b Dependent Variable: GROWTH OF MSMEs

Results in table 5 are ANOVA results that describe the overall variance accounted for in the model. The F-statistic represents a test of null hypothesis that the expected values of regression coefficients are equal to each other and that they are equal to zero or whether the $\mathrm{R}$ square proportion of variance in the dependent variable accounted for by predictors is zero. However, the larger F- Value (43.802) and small significance level $(\mathrm{P}<0.05)$ show that the three predictors are not equal to each other and could be used to predict the dependent variable, the growth of MSMEs.

Table 6. Standard Regression table showing the effect of each individual Predictor Variable.

\begin{tabular}{|c|c|c|c|c|}
\hline \multicolumn{5}{|c|}{ Coefficients (a) } \\
\hline \multirow{2}{*}{\multicolumn{2}{|c|}{ Model }} & \multicolumn{2}{|c|}{ Unstandardized Coefficients } & \multirow{2}{*}{$\begin{array}{l}\text { Standardized Coefficients } \\
\text { Beta }\end{array}$} \\
\hline & & B & Std. Error & \\
\hline \multirow[t]{6}{*}{1} & (Constant) & -.311 & .306 & \\
\hline & On average, our firm has a high amount of earnings per share & .449 & .049 & .491 \\
\hline & On average, our firm's market share has been increasing & .346 & .053 & .352 \\
\hline & On average, our firm's sales have been increasing & .085 & .058 & .087 \\
\hline & On average, our firm's capital base has been increasing & .140 & .0533 & .574 \\
\hline & On average, our firm's dividend to Shareholders has been increasing & .204 & .035 & .267 \\
\hline
\end{tabular}

a Dependent Variable: GROWTH OF MSMEs

The standardized beta coefficients for the six predictor variables in table 6 indicate that the firm's capital base is the best predictor of the growth of MSMEs (0.574), followed by EPS (0.491) followed by market share (0.352), then dividends to shareholders $(0.267)$, followed by sales $(0.087)$ and lastly the number of employees (-.063).

\section{Conclusion and Recommendations}

The growth status of MSMEs was examined using various growth indictors for MSMEs. But respondents were required to first indicate the growth status of their MSMEs after which it was tested using growth indictors that included earnings 
per share, market share, and the trend of sales, the trend of employees, the capital base and the trend of dividends.

The growth of MSMEs has been basically retarded by the ability to borrow and mode of financing where results found ignorance of the matching principle. Without this principle, firms finance short-term obligations using long-term sources of funds and consequently encroach on long-term solvency which is detrimental to the growth of the firm in the long-run. There is need to adjust the mode of financing to follow the matching principle such that long-term objects are funded using funds from long-term sources while short-term projects should be financed using funds from short term sources. This is based in the premise that short term projects should recover investments value very fast so as to be able to meet the short term obligations and vice versa. Conversely, funding short term liquidity needs using long-term sources of finance leads to a high degree of financing leverage in the long run, hence long run insolvency and decline of business.

Some respondents, especially in agriculture mentioned climatic seasons and climatic change as being great influences on their business. Research on these factors might lead to some interesting findings. For example, the alternative of irrigation rather than depending on Mother Nature may significantly impact on the cashflows, profitability and growth of the firms. Other determinants of growth which need to be studied relate to what has been referred to as human capital: the intrinsic qualities of entrepreneurs and managers, including but not limited to knowledge of the world, knowledge of business and finance, age and educational levels of the owners and managers.

\section{References}

[1] ENHANCING THE CONTRIBUTIONS OF MSMEs IN A GLOBAL AND DIGITALISED ECONOMY: Meeting of the OECD Council at Ministerial Level Paris, 7-8 June 2017.

[2] OECD (2017c), Entrepreneurship at a Glance 2017, OECD Publishing, Paris.

[3] Uganda Bureau of Statistics (2008), Statistical Abstract, Entebbe, Uganda Government Printers.

[4] UGANDA MICRO, SMALL AND MEDIUM ENTERPRISE (MSME) POLICY (2015): Sustainable MSMEs for Wealth Creation and Socio-Economic Transformation Ministry of Trade, Industry and Cooperatives (MTIC) June 2015.

[5] African development Bank Report, (2008).

[6] Lundvall, B. A. \& Johnson, B. (2009): The Learning Economy. Journal of Industry Studies 1: 23-42.

[7] Ana Paula Silva (2012) Financial and Strategic Factors Associated with the Profitability and Growth of SME in Portugal, International Journal of Economics and Finance Vol 4 no 3, March 2012.

[8] Yao Wang (2016): What are the Biggest Obstacles to the Growth of SMEs in Developing Countries http:/httpwww.elsevier.com/Journals/borsa-istanbulreview/2214-8450
[9] Joseph Otieno Oluoch (2016): The Impact of Cash Management Practices on Performance of SMEs: A Survey of SMEs in Eldoret Central Business District, IOSR Journal of Economics and Finance (IOSR-JEF) e-ISSN: 2321-5933, pISSN: 2321-5925. Volume 7, Issue 6 Ver. III (Nov. - Dec. 2016), PP 01-07 www.iza.org/en/webcontent/personnel/vitae/1201_cv.pdf.

[10] Gitman, L. J. (2009), "Estimating corporate liquidity requirements: a simplified approach", The Financial Review, Vol. 9 pp. 79-88.

[11] La Porta, R., Lopez de Silanes, F., Shleifer, A., Vishny, R. (2007), "Legal determinants of external finance", Journal of Finance, Vol. 52 pp. 1131-50.

[12] Ahmad Al-Tit, Anis Omri, Jalel Euchi (2019) Critical Success Factors of Small and Medium-Sized Enterprises in Saudi Arabia: Insights from Sustainability Perspective, http://www.mdpi.com

[13] Camp, W. G. (2001). Formulating and Evaluating Theoretical Frameworks for Career and Technical Education Research. Journal of Vocational Educational Research, 26 (1), 27-39.

[14] Grant, C. \& Osanloo, A. (2014). Understanding, Selecting, and Integrating a Theoretical Framework in Dissertation Research: Creating the Blueprint for 'House'. Administrative Issues Journal: Connecting Education, Practice and Research, Pp. 12-22 DOI: 10.5929/2014.4.2.9.

[15] Philip Kotler (2017): some of my adventures in marketing, Journal of Historical Research in Marketing 9 (2).

[16] Oluwatayo, J. (2012). Validity and reliability issues in educational research. Journal of Educational and Social Research 2, 391-400.

[17] Roberta Heale, Alison Twycross (2019), Validity and reliability in quantitative studies, Evid Based Nurs July 2015/vol 18/ Number 3.

[18] Shuttleworth M. Internal Consistency Reliability. 2015. https:/explorable.com/internal-consistency-reliability.

[19] Hamed Taherdoost (2016) Validity and Reliability of the Research Instrument; How to Test the Validation of a Questionnaire/Survey in a Research, International Journal of Academic Research in Management (IJARM) Vol. 5, No. 3, 2016, Page: 28-36, ISSN: 2296-1747 C Helvetic Editions LTD, Switzerland www.elvedit.com

[20] rigour

[21] A. F. (2018). Healthcare Cost Savings over a One-year Period for Silver Sneakers Group Exercise Participants. Health Behavior and Policy Review, 5 (1), 40-46.

[22] Cronbach, L. J. (2001), Coefficient alpha and the internal structure of tests. Psychometrika. 16, 297-334.

[23] McGarland, R. \& Rauch, S. (2003). Objectifying content validity: conducting a content validity study in social work research.

[24] Lobiondo-Wood G (2013) Haber Nursing research in Canada. Methods, critical appraisal, and utilization. 3rd Canadian edition. Toronto: Elsevier, 2013.

[25] Weinreich, N. K., (2006). Integrating Quantitative and Qualitative Methods in Social Marketing Research. Social Marketing Quarterly. Retrieved from http://www.socialmarketing.com/research.html]. 